\section{Having the final word. . .}

SIR-I do not know whether there are still Creationists who believe that God created the world with implanted fossils and strata records (and similarly a Universe with implanted galactic records); but, if there are, then Bruce Denness's letter "Divine artefact" (Nature 336, 614; 1988), raises a problem that should be of great concern to them.

"God is not a man, that He should lie" (Numbers 23:19). Yet the suggestion that God could have created a world, or Universe, in which a record of the past was 'implanted', implies that he has lied. And the consequences to faith could be more shattering than they are to science.

First: if (arguendo) the Earth and Universe are (say) only 20,000-odd years old, but have been created to appear respectively about $5 \times 10^{4}$ and $20 \times 10^{9}$ years old, then these greater ages are without doubt their scientific ages - there is no way that science can come up with an age of 20,000 years. To understand this, consider what the scientific ages of brand-new but exact copies of this Earth and Universe would be, if God chose to make such copies.

Second, it becomes a matter of faith alone, under such circumstances, that the age of the Earth or Universe is anything other than what it appears to be scientifically. And only faith can govern the selected age. But why, under such circumstances, should any particular age be arbitrarily chosen? Creationists may interpret the Bible as implying one age rather than another; but the Earth could have been created some year ad with Bibles intact as part of the implanted record. How is one to prove that that did not occur? But if it did, then Jesus was not born on Earth and did not die for us; nor was he resurrected. What happens, then, to our salvation? So, to believe that God could have created an Earth or Universe with an implanted record ultimately strikes at the heart of the Christian faith. Maybe quite a headache for Creationists.

Perhaps there is no scientific answer to the problem Denness raises, but only a theological one.

\section{Fieldstone Drive,} Whippany, New Jersey 07981, USA

SiR-I find that it has become necessary, for a second time (see Nature 323, 754; 1986), for $\mathrm{Me}$ to intervene in order to present My Word in these pages.

Unless I have misunderstood matters (which is unlikely), I am depicted by some individuals as a sort of Divine Con-Artist (Nature 336, 614; 1988 and 337, 498; 1989), allegedly creating the Universe, and then disguising this fact, for reasons apparently known only to Myself. Others find it beholden upon themselves to rush to My defence and deny this, because they have decided that it reflects poorly on My Divine Logic.

I had hoped that My previous Correspondence in these columns had made clear that all speculation of any kind on My Nature is unwelcome, from both an epistemological and a Personal view. In particular, if ever again I read Professor Einstein's remarks to the effect that, whilst I am Cunning, I am not Malevolent, the extent of My lack of malevolence will be sorely tested. It is not that I disapprove of Professor Einstein's flattering description, it is that even $M y$ Patience, Infinite though It is known to be, is beginning to crack at the many, many repetitions I see of that comment. One other observation I hope never to be quoted again, at least for a long time, is Professor Haldane's, the one about the cosmos being not only stranger than one imagines but ... you know how it goes. Whilst apposite, I feel it needs a rest.

But I digress (which is one of the qualities One finds in Omnipotence).

A periodical ostensibly concerned with matters of scientific interest would do well to think carefully before allowing speculations of a totally metaphysical nature space in which to appear. I certainly would hope that I am as disposed to be as Broadminded as the next Entity and that no-one would accuse $\mathrm{Me}$ of desiring to fetter a free press, particularly in this country at this time, but I commend the matter to your most earnest consideration, if you get My drift.

I trust I shall not have to bring this to your attention on a third occasion.

(As revealed to Ralph Estling)

The Old Parsonage,

Dowlish Wake,

IIminster,

Somerset TA19 ONY, UK

It is to be hoped that putative correspondents will take the hint. Editor, Nature.

\section{Intuitive science}

SIR-I have been reading The Value of Science by Henri Poincaré, who believed that intuition and logic make science advance. Intuitive scientists work in figures and imagination; in mathematics, they are its geometers. Logic scientists go from the particular to the general; they are the analysts in mathematics.

As a biochemist who agrees with Poincaré, I ask: what is the contribution of logicians and analysts to the advance of biochemistry? From the biochemical journals, it seems that only logicians exist. All hypotheses, even if they are subsequently shown to be wrong, are based on experi- mental results presented in a formal and statistically rigorous way.

I believe that intuitive biochemists exist, but that their contributions have to be communicated in the form required by the journals, in analytic form. Hypotheses that are intuitive in nature are not considered suitable for biochemical journals.

Yet Poincaré points out that intuitive work is even more important than analytical work for the advance of science. In biochemistry, it sometimes seems that analytical work is performed without any precise objective. The thousands of articles in the journals contribute very little to the advance of knowledge. That is why two urgent needs in biochemistry are (1) the study of all the available information in order to advance intuitive hypotheses and (2) the recognition and promotion of intuitive biochemists through publication of that work. To these ends, journals should change their policies without lowering their quality.

Poincaré said it clearly: "Pure logic does not lead to anything but tautologies; it creates nothing new".

\section{Department of Biochemistry and}

RAFAel Franco

Physiology,

University of Barcelona,

Diagonal 647 ,

08028 Barcelona,

Spain

\section{History lesson}

SIR-You remark in your unsigned Commentary article marking the fiftieth anniversary of the discovery of uranium fission' that to suppose that "some history is so painful that nothing can be learned from it

. is a disservice to the intellect" bears on three items in the previous issue of your journal $^{2-4}$ dealing with quark matter and strange matter. In the News and Views piece on the subject ${ }^{2}$, we find the statement that the growth phase of quark nuggets caused by the addition of low-energy neutrons "releases of the order of 20 megaelectron volts of energy yield per captured neutron . . . nearly 10 times the yield per neutron in a conventional fission reactor".

Let us hope that the human intellect has matured enough in the intervening 50 years to learn from past experience, and that if the proposal of Shaw et al. ${ }^{3}$ for quark matter engineering turns out to be successful, you will be able to write a different kind of Commentary for Nature in 2039.

\section{CARLO PISCICELLI-TAEGGI}

Via Ippolito Nievo, 28/A,

\section{Milano,}

Italy

1. Nature 337, 499-502 (1989).

2. Alcock, C. Nature 377, 405 (1989)

3. Shaw, G.L., Shin. M., Dalitz, R.H. \& Desai, M. Nature 337, 436-439 (1989).

4. Brügger, M. et al. Nature 337, 434-436 (1989) 